\title{
In vitro photodynamic therapy in pediatric epithelial liver tumors promoted by hypericin
}

\author{
GUIDO SEITZ ${ }^{1}$, RENITA KRAUSE ${ }^{1}$, JÖRG FUCHS ${ }^{1}$, HEIKE HEITMANN ${ }^{1}$, \\ SORIN ARMEANU ${ }^{1,2}$, PETER RUCK ${ }^{3}$ and STEVEN W. WARMANN ${ }^{1}$ \\ ${ }^{1}$ Department of Pediatric Surgery, University Children's Hospital Tübingen, Hoppe-Seyler-Str. 3, 72076 Tübingen; \\ ${ }^{2}$ Department of Internal Medicine I, Medical University Clinic, Otfried-Mueller-Str. 10, 72076 Tübingen; \\ ${ }^{3}$ Institute of Pathology, Rutesheimer Str. 50/1, 71229 Leonberg, Germany
}

Received May 16, 2008; Accepted July 7, 2008

DOI: 10.3892/or_00000141

\begin{abstract}
Limited treatment results in advanced pediatric liver tumors have emphasised the need for alternative treatment approaches in these malignancies. Photodynamic therapy (PDT) has been proposed as promising treatment approach in various malignancies. Hypericin, a naturally occurring substance found in the St. John's Wort, has regularly and successfully been used for visualisation and as photosensitizer in various tumor models. However, there exist no data on the effects of hypericin as photodynamic agent in pediatric malignant epithelial liver tumors. In this study, we investigated the potential role of hypericin for visualization and treatment in hepatoblastoma (HB) and pediatric hepatocellular carcinoma (HCC) cells. Two HB cell lines (HUH6, HepT1) and one HCC cell line (HepG2) were incubated with ascending concentrations of hypericin. Uptake and fluorescending capability were assessed using fluorescence microscopy and FACS. PDT with white light was performed for varying time intervals. Cell viability, cell proliferation and apoptotic rates were assessed using MTT assay, Ki-67 immunocytochemisty and TUNEL test, respectively. The changes within tumor cells under therapy were monitored using standard cytology. Relevant hypericin uptake was observed in all cell lines according to the applied concentrations. Histological analysis revealed no alterations of cell structure in HB and HCC cells after solely hypericin uptake, but severe alterations were found after PDT. Enhancement of the hypericin concentration (up to $12.5 \mu \mathrm{M}$ ) and illumination time of up to 40 min resulted in a decrease of tumor cell viability (HUH6 99.8 $\pm 2.4 \%$, HepT1 $99 \pm 2 \%$, HepG2 $98.4 \pm 1.6 \%, \mathrm{p}<0.05$ ), proliferative activity and complete apoptosis of all cells in all investigated cell lines.
\end{abstract}

Correspondence to: Dr Guido Seitz, Department of Pediatric Surgery, University Children's Hospital Tübingen, Hoppe-SeylerStr. 3, 72076 Tübingen, Germany

E-mail: guido.seitz@med.uni-tuebingen.de

Key words: hepatoblastoma, hepatocellular carcinoma, photodynamic therapy, hypericin
These data show that hypericin might be a useful tool for visualisation and as alternative treatment option in $\mathrm{HB}$ and HCC.

\section{Introduction}

Human hepatoblastoma (HB) is the most common primary malignant liver tumor in infants and children. During the past decades improvements of treatment results were achieved in standard tumors. Standard risk HB-patients have a 3-year overall survival of $91 \%$ and within this group, disease-free survival in stage I and II patients is $98-100 \%$. However, advanced $\mathrm{HB}$, relapsed or metastasized tumors still are associated with a poor prognosis. The 3-year overall survival rate for patients with high-risk $\mathrm{HB}$ is $53 \%$ and the disease-free survival in stage IV is $\sim 36 \%(1,2)$. Hepatocellular carcinoma (HCC) is a rare tumor entity in children. The outcome of these patients is worse compared to hepatoblastoma (3). The 5 -year overall survival is $28 \%$ and the event-free survival $>75$ months is only $17 \%$ (4). In order to improve those data, additional approaches have become necessary especially since no essential progress has been achieved by established treatment options.

Photodynamic therapy (PDT) is a novel anticancer approach based on administration of a non- or weakly-toxic photosensitizer. PDT depends on the delivery of a photosensitizer to the target tissue. Light exposure with light of the appropriate wavelength causes production of singlet oxygen (5), which causes apoptotic cell death (6).

Hypericin is a hydroxylated phenanthroperylenequinone derivate and is found in plants of the St. John's Wort (7). The most common species is Hypericum perforatum (8). Hypericin is currently under evaluation for different tumor types such as rhabdomyosarcoma (7), nasopharyngeal carcinoma (9) or colon carcinoma (5). Besides its photodynamic abilities, it can be also used for the detection of tumor cells in vivo (10). Up to now, there is no data on PDT in liver malignancies.

The aim of this study was to evaluate the effects of hypericin-induced photodynamic therapy as a novel promising treatment option for advanced stage hepatoblastoma and hepatocellular carcinoma in vitro. Furthermore, we wanted to figure out if in vitro visualization of tumor cells might be 
feasible and could improve the identification of safety margins in liver surgery.

\section{Materials and methods}

Cell lines and culture conditions. The cell line HUH6 originates from a mixed HB. The tumor presents chondroosteogenetic tissue and extra medullar haematopoiesis. Tumor cells have a caryotype with 48 chromosomes (11). The cell line HepT1 was derived from an embryonal HB. The caryotype is polyploid with $65-125$ chromosomes per cell, deletions on $1 \mathrm{p}$ and $11 \mathrm{q}$ and a $6 \mathrm{q} 15$ translocation (12). The cell line HepG2 was derived from a pediatric hepatocellular carcinoma of trabecular type. The caryotype consists of 50-56 chromosomes per cell with several isoforms of chromosome 1. The hepatitis B surface antigen ( $\mathrm{HbsAg}$ ) is also expressed (13).

All tumor cells were grown as monolayer in Dulbecco's MEM medium (Biochrom, Berlin, Germany) supplemented with $10 \%$ fetal calf serum, $1 \%$ glutamine and $2.5 \%$ HEPES buffer (Gibco, Eggenstein, Germany). The cells were grown at $37^{\circ} \mathrm{C}$ in a humidified atmosphere containing $5 \%$ carbon dioxide. All cells were mycoplasma species negative.

Hypericin experiments. HUH6, HepT2 and HepG2 cells $\left(5 \times 10^{4}\right)$ were seeded out in 8 -well chamber slides (Falcon Becton-Dickinson Labware, Franklin Lakes, NJ, USA, \#354108, $200 \mu \mathrm{l} /$ well) and were cultured as described before (1). After $24 \mathrm{~h}$, the medium was removed and hypericin (Phytochem, Neu-Ulm, Germany) dissolved in DMSO was added in increasing concentrations $(0,2.5,5,7.5,10$ and $12.5 \mu \mathrm{M})$. Cells were incubated for $2 \mathrm{~h}$ in a humified atmosphere containing $10 \% \mathrm{CO}_{2}$ at $37^{\circ} \mathrm{C}$ without exposure to light. After an incubation time of $2 \mathrm{~h}$, the hypericin solution was replaced by standard medium. Fluorescence microscopy [Zeiss AxioVision, Jena, Germany, filter set 15, \#4880150000 , excitation $546 \mathrm{~nm}(+12 /-12 \mathrm{~nm})$, emission 570-650 nm, emission $590 \mathrm{~nm}$ ] was taken to evaluate hypericin uptake in cancer cells.

For photodynamic therapy, cells were treated as described above and additionally exposed to white light (1000 Lux, Osram, Germany) under a clean bench (Heraeus, HLB 2472 GS, Germany) for $0,10,20,30,40$ or $50 \mathrm{~min}$. Cells were cultured in the dark up to day 5. MTT assay, Ki-67 assay and TUNEL test were performed at day 5, as described below.

Cell morphology. Cancer cells were examined for possible changes in cell morphology after hypericin treatment by a pathologist. Therefore, light microscopy was used. Tumor cells without application of hypericin (controls), after hypericin treatment $(0,2.5,5,7.5,10$ and $12.5 \mu \mathrm{M})$ without exposure to light, and after hypericin treatment $(0,2.5,5,7.5$, 10 and $12.5 \mu \mathrm{M}$ ) with exposure to light for 0,10 , and $50 \mathrm{~min}$ were investigated.

FACS analysis. Cells were incubated with above-mentioned hypericin concentrations for $2 \mathrm{~h}$ until trypsination. All experiments were performed in the dark. Hypericin uptake was analysed using a FACS CANTO flow cytometer (BD
Heidelberg, Germany) and Flow Jo Software (Tree Star Inc., Stanford, USA). Fluorescence intensity of hypericin was detected using a blue-green laser with excitation at $488 \mathrm{~nm}$ and emission at $575 \mathrm{~nm}$. The percentage of labelled cells and mean fluorescence intensity of labelled cells were calculated using unlabelled cells as background. The hypericin uptake was estimated by the mean fluorescence index (MFI), which was the ratio between the mean fluorescence of the positive cell population and of the negative control.

Cell viability. Cell viability was assessed using the MTT [3-(4,5-dimethylthiazol-2-yl)-2,5-diphenyltetrazolium bromide]-assay (Biomedica EZ4U, Biozol, Germany) at day 5. Therefore, substrate was dissolved in activator solution and $20 \mu \mathrm{l}$ was added to each well. Incubation time was $5 \mathrm{~h}$. Afterwards, absorption was measured by an ELISA reader (Tecan Spectra Mini, Grödig, Austria) at $450 \mathrm{~nm}$ against a reference at $620 \mathrm{~nm}$.

Cell proliferation. In order to investigate cell proliferation, a Ki-67 immunocytochemistry assay was carried out at day 5 . A hypericin concentration of $5 \mu \mathrm{M}$ was used due to complete destruction of tumor cells at higher concentrations. Cells were rinsed in PBS and then fixed with Roti-Histofix (Roth, \#2213.3, Karlsruhe, Germany) for $10 \mathrm{~min}$. After fixation, cells were rinsed in PBS for 5 min. Blocking was performed using $1.5 \%$ normal goat serum (Dako, \#X0907, Glostrup, Denmark) for $30 \mathrm{~min}$ followed by monoclonal mouse anti-human Ki-67primary antibody-clone MIB-1 (Dako Cytoformation, \#M7240, Glostrup, Denmark, dilution 1:100) for $60 \mathrm{~min}$ at room temperature. Slides were rinsed for $3 \times 5 \mathrm{~min}$ in PBS. A FITC-conjugated secondary goat anti-mouse antibody (Dianova, \#115-095-062, Hamburg, Germany, dilution 1:100) was added for $30 \mathrm{~min}$ at room temperature, followed by a PBS washing step $(3 \times 5 \mathrm{~min})$. For counterstaining of the nucleus, DAPI was used for 1 min (Sigma-Aldrich, \#D-9452, Germany, dilution 1:10000) followed by another PBS washing step. Slides were mounted (Dako mounting medium, Glostrup, Denmark) and analyzed using fluorescence microscopy (Zeiss AxioVision). Therefore, 300 cells per slide were counted in triplicate.

TUNEL test. Detection of possible apoptosis in cancer cells was revealed by a Terminal deoxyribosyl-transferasemediated dUTP nick-end labeling test (TUNEL). This test was performed at day 5. Different concentrations of hypericin $(0,2.5,5,7.5,10$ and $12.5 \mu \mathrm{M})$ and irradiation times of 0,10 and $50 \mathrm{~min}$ were used for these experiments. Chambers were removed and slides were rinsed in PBS. Cells were than fixed with Roth-Histofix (Roth, Munich, Germany) and again rinsed in PBS (3 times). Slides were incubated in $0.1 \%$ Triton/PBS (Merck, Darmstadt, Germany) on ice for $2 \mathrm{~min}$ and rinsed with PBS again. TUNEL reaction solution (50 $\mu 1 /$ well, Roche Diagnostics, \#1684795, Pinzberg, Germany) was added for $60 \mathrm{~min}$ at $37^{\circ} \mathrm{C}$. For positive controls, cells were incubated with DNase I (1:10 in PBS, $15 \mathrm{~min}$ at room temperature, Roche Diagnostics). The TUNEL reaction solution was added, as described above. For negative controls, $50 \mu 1 /$ well of labelling solution (Roche Diagnostics, \#1684795) was added. Slides were rinsed in PBS (x3). For nuclear counterstaining, 


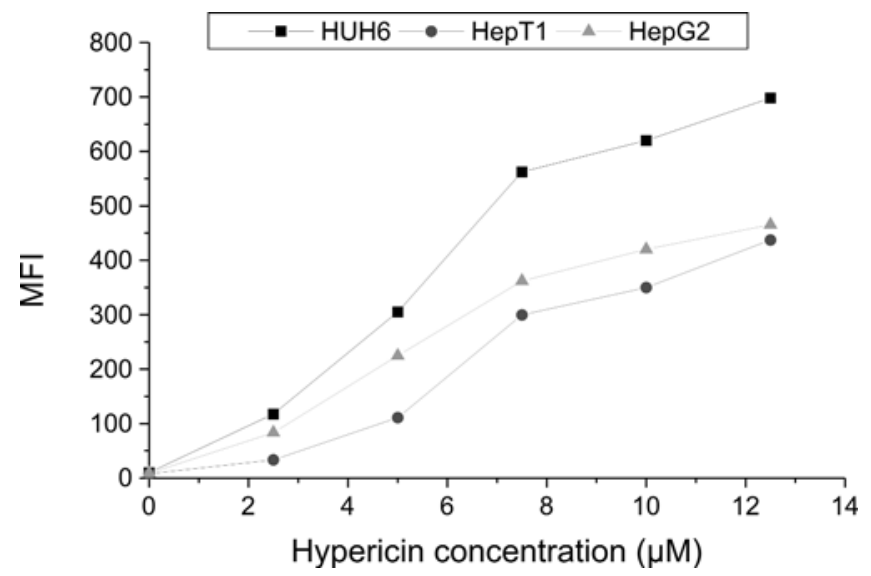

Figure 1. Quantitative assessment of hypericin uptake using FACS analysis. An increasing hypericin uptake was observed with increasing hypericin concentrations (MFI, mean fluorescence index).

DAPI was used for 1 min (Sigma-Aldrich, dilution 1:10000) followed by $3 \times 5$ min PBS. Slides were mounted, as described above and analyzed by fluorescence microscopy. Therefore, 300 cells per slide were counted in triplicate.

Statistical analysis. Statistical analysis on cell vitality (MTT assay), Ki-67 immunocytochemistry and TUNEL-test was performed between the groups using one way ANOVA on ranks test. Data were tested against a control group (hypericin $0 \mu \mathrm{M}, 0$ min illumination time) using a Dunn's test. All numeric data are expressed as mean \pm SEM. Significance was assumed for all $\mathrm{p}<0.05$. FACS data were analyzed by linear regression and slope confidence intervals of MFI vs. concentration curves using GraphPad Prism software (Version 4.00 for windows, GraphPad Software, San Diego, CA, USA).

\section{Results}

Biodistribution. A hypericin uptake was found in all tumor cell lines leading to a strong fluorescence signal. Quantitative assessment of cellular hypericin fluorescence using FACS analysis showed increasing uptake of hypericin with increasing concentrations in HUH6, HepT1 and HepG2 cell lines. The highest fluorescence signal was found in HUH6 cells (MFI 697.83) and lowest fluorescence signal in HepT1 (MFI 437.14) (Fig. 1).

Cell morphology. Possible changes in cell morphology after photodynamic therapy were analysed by light microscopy. Cell lines after application of hypericin without exposure to light and negative controls exhibited large sheets and clusters of tumor cells with epithelial features. The tumor cells showed a high nuclear cytoplasmic ratio with large nuclei containing prominent nucleoli. After photodynamic treatment the density of cells and cell cohesion were reduced and the clusters of cells were smaller. The effect was dependent on the concentration of hypericin and the duration of photodynamic treatment. When treatment was carried out for $50 \mathrm{~min}$ and at high hypericin concentrations $(12.5 \mu \mathrm{M})$, there were usually few clusters of cohesive cells left and scattered cells with pyknotic nuclei were found.

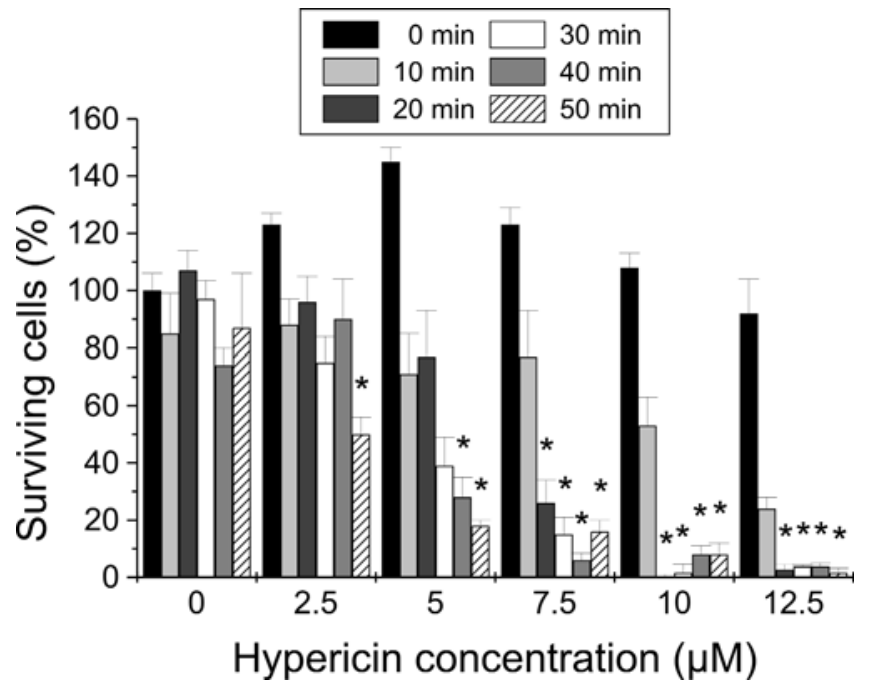

Figure 2. Cell vitality after PDT in hepatocellular carcinoma HepG2 cells. PDT with $10 \mu \mathrm{M}$ hypericin and illumination times $>20$ min resulted in a nearly complete reduction of vital tumor cells $[\mathrm{p}<0.05$ vs. control group (hypericin $0 \mu \mathrm{M}, 0$ min light exposure)]

Cell viability. Illumination with white light without application of hypericin had no effect on tumor cell viability in any of the cell lines. Application of increasing concentrations of hypericin without illumination showed an increase in tumor cell viability in all tumor cell lines. The highest tumor cell viability was found at the highest hypericin concentration $(50 \mu \mathrm{M})$ in both hepatoblastoma cell lines (HepT: $121 \pm 9.5 \%$, HUH6 131 $15 \%$ ). In the hepatocellular carcinoma cell line HepG2, the highest cell viability was found at a concentration of $5 \mu \mathrm{M}$ hypericin $(145 \pm 5 \%)$. Enhancement of the hypericin concentration and illumination time resulted in a decrease of tumor cell viability in all cell lines. In the hepatocellular carcinoma cell line HepG2, a minimum hypericin concentration of $10 \mu \mathrm{M}$ hypericin and an illumination time of $20 \mathrm{~min}$ or more were required to kill nearly all tumor cells $(98.4 \pm 1.6 \%, \mathrm{p}<0.05$, Fig. 2). In the hepatoblastoma cell line HepT1, a hypericin concentration of $12.5 \mu \mathrm{M}$ hypericin and exposure to light for 30 min was required to destroy $99 \%$ of the cells $( \pm 2, \mathrm{p}<0.05$, Fig. 3). In the hepatoblastoma cell line HUH6, a hypericin concentration of $12.5 \mu \mathrm{M}$ hypericin and an illumination time of $40 \mathrm{~min}$ were necessary to kill $99.8 \%$ of the cells $( \pm 2.4$, p<0.05, Fig. 4).

Cell proliferation. Ki-67 immunocytochemistry revealed a reduction of proliferating cells with increasing concentrations of hypericin and exposure to light. After incubation with $5 \mu \mathrm{M}$ hypericin and exposure to light for $20 \mathrm{~min}$, a significant reduction of the proliferative activity was detected in all cancer cells (HepT1: 70\%, HUH6: 46\%, HepG2: $46 \%, \mathrm{p}<0.05$ compared vs. control $0 \mu \mathrm{M}, 0 \mathrm{~min})$. At illumination times of $50 \mathrm{~min}$ in HUH6 cells, the number of Ki-67-positive cells was also lower, but some proliferating cells could still be detected $(3.7 \pm 0.89$ cells, $\mathrm{p}<0.05$ vs. control). In HepT 1 and HepG 2 cell lines only few proliferating cells could be detected after $50 \mathrm{~min}$ (HepT1: $1.7 \pm 0.3$ cells, HepG2: $1.7 \pm 0.3$ cells, $\mathrm{p}<0.05$ vs. control, Fig. 5). 


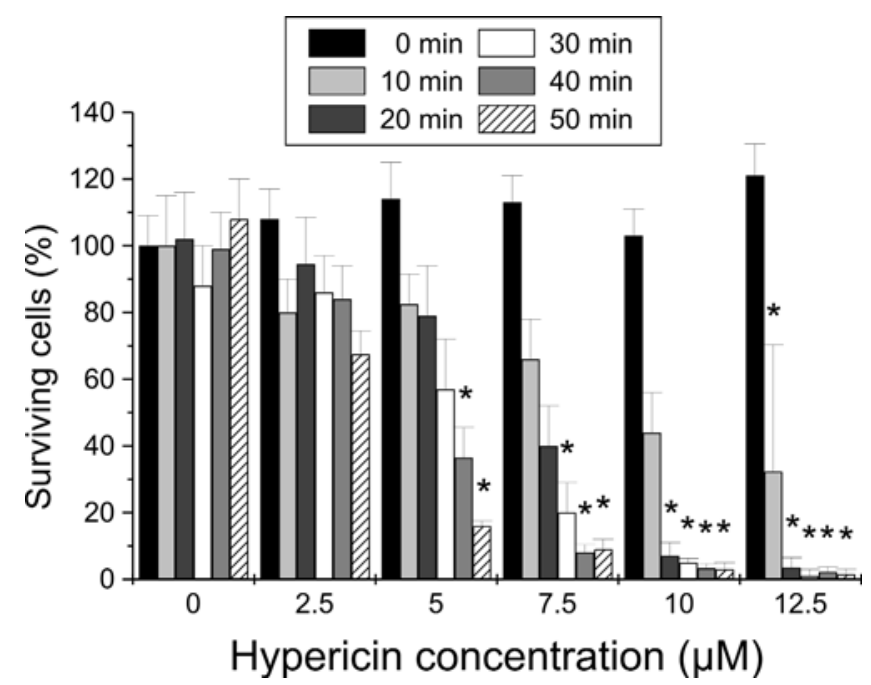

Figure 3. Cell vitality after PDT in hepatoblastoma HepT1 cells. PDT with hypericin at concentrations of $12.5 \mu \mathrm{M}$ and illumination over $20 \mathrm{~min}$ resulted in a nearly complete disappearance of vital tumor cells $[\mathrm{p}<0.05$ vs. control group (hypericin $0 \mu \mathrm{M}, 0 \mathrm{~min}$ light exposure)].

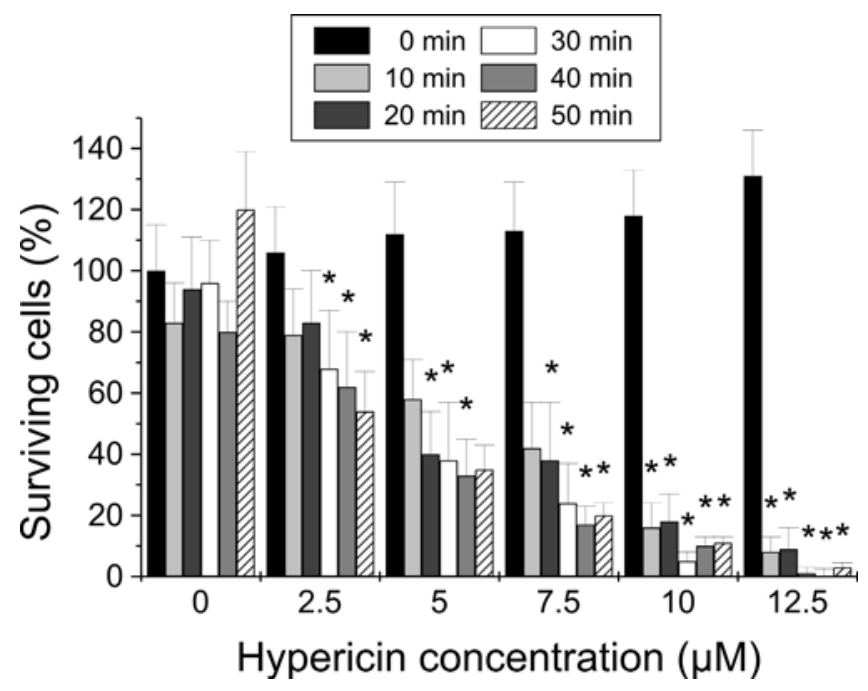

Figure 4. Cell vitality in hepatoblastoma HUH6 cells after PDT. PDT with hypericin concentrations of $12.5 \mu \mathrm{M}$ hypericin and illumination times $>20 \mathrm{~min}$ resulted in a nearly complete reduction of vital tumor cells [p $<0.05$ vs. control group (hypericin $0 \mu \mathrm{M}, 0 \mathrm{~min}$ light exposure)].

Apoptosis. TUNEL test revealed apoptotic tumor cells with increasing hypericin concentrations and illumination times in all cell lines. In hepatocellular carcinoma cells, PDT with a hypericin concentration of $2.5 \mu \mathrm{M}$ hypericin and illumination for 50 min caused a significant increase in apoptotic cells $(\mathrm{p}<0.05)$. At a hypericin concentration of $10 \mu \mathrm{M}$ and illumination for $50 \mathrm{~min}$, only apoptotic cells could be found (Fig. 6).

In HUH6 hepatoblastoma cells, less apoptotic cells were found compared to hepatocellular carcinoma at lower concentrations $(<7.5 \mu \mathrm{M})$ and exposure to light for 0 or $20 \mathrm{~min}$. At higher concentrations and longer illumination times, higher numbers of apoptotic cells were detected. For comparable effects, a PDT with higher hypericin concentrations $(12.5 \mu \mathrm{M})$ and longer illumination times were required (Fig. 7).

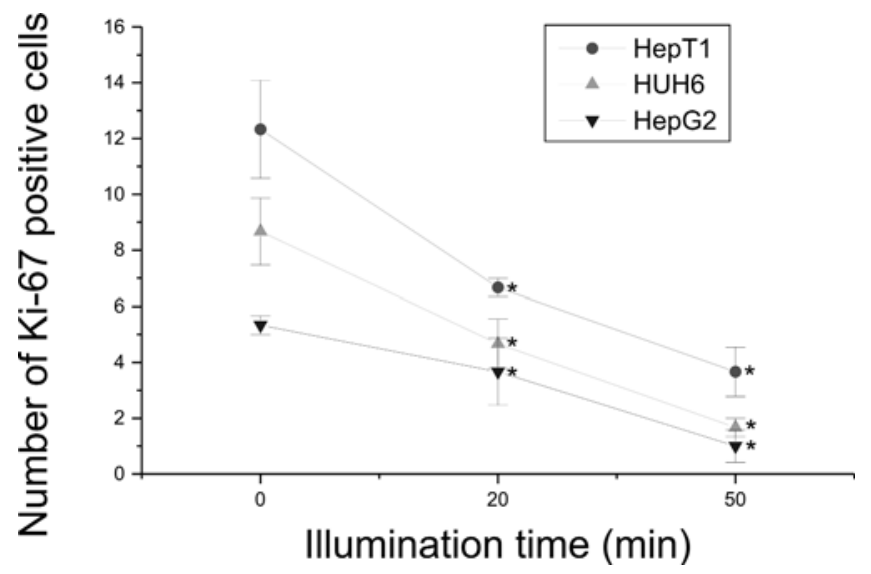

Figure 5. Number of Ki-67-positive cells after incubation with $5 \mu \mathrm{M}$ hypericin and exposure to light for 0,20 and $50 \mathrm{~min}$. A reduction of cell numbers was found with increasing illumination times ( $\mathrm{p}<0.05$ vs. control).

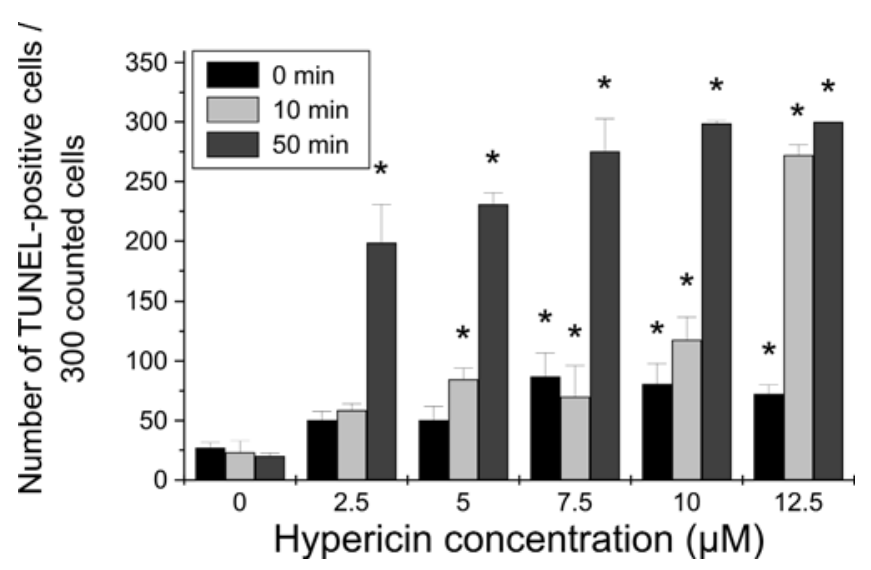

Figure 6. TUNEL test in hepatocellular carcinoma cell line HepG2. Increasing hypericin concentrations and illuminations times caused higher numbers of apoptotic cells.

In HepT1 hepatoblastoma cells, similar results were found as in HUH6 cells. At a hypericin concentration of $12.5 \mu \mathrm{M}$ and exposure to light for $50 \mathrm{~min}$ only apoptotic cells were found (Fig. 8).

\section{Discussion}

Photodynamic therapy (PDT) is used as a novel treatment option in various malignancies. Activation of the photodynamic drug by light results in the development of singlet oxygen radicals which induce cytotoxic effects on cancer cells (14). One of the most promising substances today is hypericin, an extract from St. John's Wort, which is a herbacecous occurring plant in Europe and Asia (10). Hypericin was initially used as an antidepressive drug (15), but is nowadays studied as a photodynamic agent in different cancer types such as bladder carcinoma (16), colonic cancer (17), glioblastoma (18), nasopharyngeal carcinoma (19) and rhabdomyosarcoma (7). Besides photodynamic effects of hypericin, the substance can be also used for in vivo detection of cancer cells. Most promising effects have been described in the diagnosis of bladder carcinoma by cystoscopy (10). Hypericin can also be 


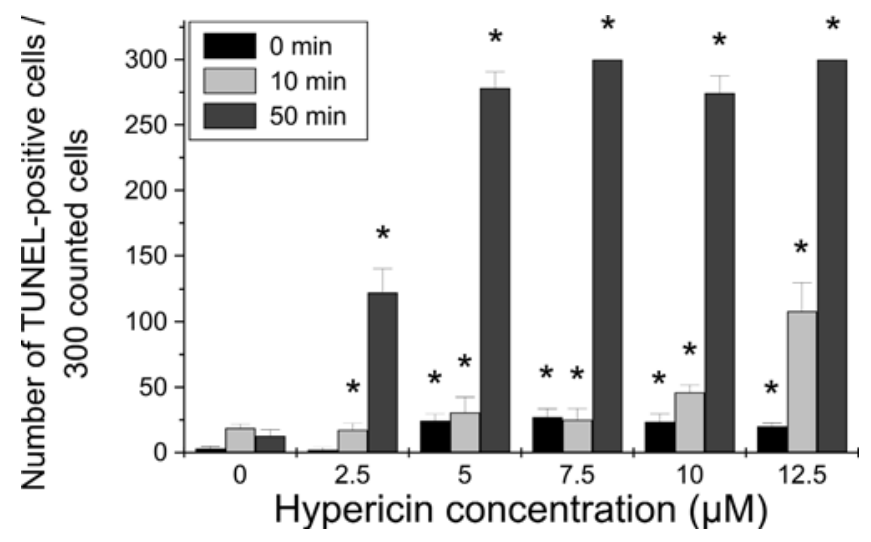

Figure 7. TUNEL test in hepatoblastoma cell line HUH6. Increasing hypericin concentrations and illuminations times caused higher numbers of apoptotic cells.

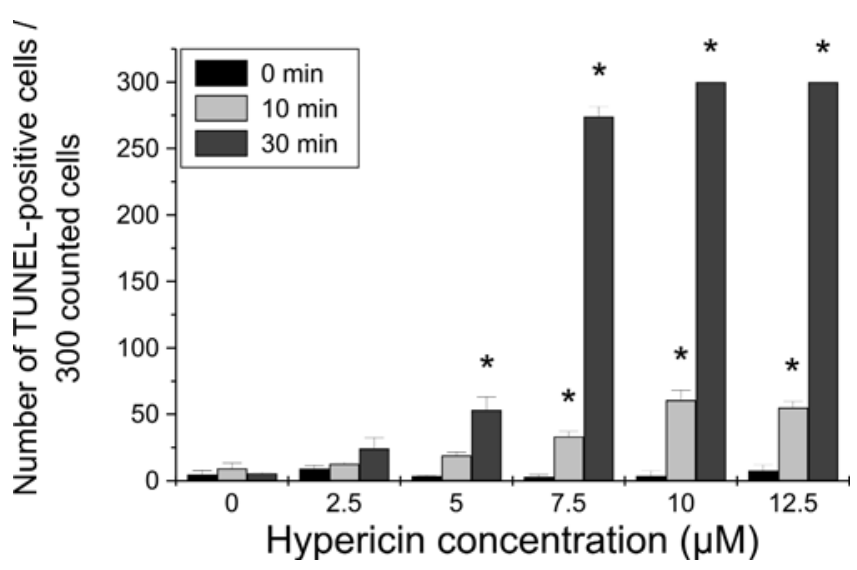

Figure 8. TUNEL test in hepatoblastoma cell line HepT1. Increasing hypericin concentrations and illuminations times caused higher numbers of apoptotic cells.

used for ex vivo fluorescence detection of bladder cancer using urine cytology, which allows non-invasive diagnosis of bladder cancer (20).

Hypericin internalization in cancer cells seems to be a result of three mechanisms: partitioning, pinocytosis and endocytosis (21). Hypericin is mainly found in the endoplasmatic reticulum (21). Interestingly, hypericin uptake is preferentially found in cancer cells $(7,14,22,23)$ and anti-tumor effects of PDT on tumor cells are stronger than in controls (7). Therefore, hypericin uptake is thought to be tumor-specific (7).

Hepatoblastoma (HB) is the most common malignant pediatric liver tumor. The outcome of patients with advanced tumor stages is still sobering. Therapy is limited to radical surgery and chemotherapy. Radiation therapy has no effect on this tumor entity (24). Hepatocellular carcinoma (HCC) in children is a rare disease associated with a poor outcome. Tumors are rarely chemosensitive and radiation therapy has no benefit on the survival of these patients. Complete radical tumor resection is essential for the survival and is one of the main prognostic factors for survival (3). Besides liver resections, liver transplantation is an increasingly important treatment option for HB and HCC in selected cases (25). However, novel diagnostic and therapeutic options are desirable leading to investigation on alternative treatment approaches such as hypericin PDT.

In our study, we evaluated the effects of hypericin induced photodynamic therapy in pediatric hepatoblastoma and hepatocellular carcinoma cell lines in order to find new treatment approaches for these tumor entities. We found a complete uptake of hypericin in tumor cells depending on applied doses. Fluorescence intensity differs from cell line to cell line and might depend on the tumor cell size. In large tumor cells, hypericin seems to be distributed on a larger area and therefore fluorescence intensity is lower than in smaller cells. A complete uptake of hypericin is essential for PDT, but also for a possible intraoperative visualization of the tumor in vivo. This would be beneficial as tumor margins are sometimes unclear during liver resections in the OR and safety margins could be placed more sufficiently.

PDT caused major changes in cell morphology leading to a destruction of cancer cells. Destruction of cancer cells using hypericin PDT has been described as being caused by apoptosis mediated via the p38(MAPK) and PI3K signalling cascades (26). Induction of apoptosis was also detected in our study by TUNEL test. At high hypericin concentrations and longer exposure to light, only apoptotic cancer cells were found.

In contrast to the observation in TUNEL test, PDT with hypericin only resulted in a reduction of the proliferative activity of the cancer cells as shown by Ki-67 immunocytochemistry, but did not cause a complete disappearence of proliferating cells. This might be caused by the applied doses. For the in vivo use of hypericin-mediated PDT even higher doses would be required in order to completely inhibit a proliferative activity. A complete prevention of cell proliferation of the tumor cells would be a major task for the clinical use of the novel therapy.

Interestingly, application of hypericin without exposure to light caused an increase in tumor cell viability. One reason therefore might be that hypericin also is able to inhibit the proteasome complex (27). Chen and Regan demonstrated that proteasome inhibitors can have a protective effect on cells, which are consecutively taking advantage resulting in increased viability (28). After exposure to light, there effects are no longer found and PDT with hypericin caused a significant reduction of tumor cell vitality. At higher concentrations $(12.5 \mu \mathrm{M})$ and illumination times (50 min), a nearly complete disappearance of tumor cells occurred. Lower doses and shorter illumination times were required in hepatocellular carcinoma. This might be caused by the biological behaviour of the tumor cell line. Interestingly, there seems to be no correlation with the observation of insufficient response of HCC to cytotoxic agents (29) as other mechanisms are involved in PDT-mediated cell death.

A possible clinical application of hypericin could be the intraoperative application of the drug during or after liver resections and exposure to the OR light. This would help on one hand to visualise tumor margins intraoperatively for instance in difficult anatomical regions such as the porta hepatis and to enable R0 resections. On the other hand, PDT could be directly applied to resection margins thus destroying microscopical rests, especially in cases of marginal or extended liver resections. 
Major side effects of hypericin-induced PDT should not be expected in infants and children as hypericin is already clinically used in different tumor entities such as bladder carcinoma without severe side effects (8). Applied doses are lower than in antidepressant therapy (30). Hypericum extracts have no mutagenic potential (31). Hypericism, a major side effect causing photodermatitis, is only to be expected at higher concentrations (32).

Taken together, we conclude that hypericin is a promising novel agent for in vivo diagnosis and in vitro photodynamic therapy of childhood hepatoblastoma and hepatocellular carcinoma. Hypericin-induced PDT seems to be effective in both tumor entities. Further in vivo studies seem justified focussing on the in vivo efficiency on this drug in childhood liver tumors. Intraoperative PDT should be easily transferable to the OR, in which the normal light system will most probably be sufficient for the therapy.

\section{References}

1. Perilongo G, Shafford E, Maibach R, Aronson D, Brugières L, Brock P, Childs M, Czauderna P, MacKinlay G, Otte JB, Pritchard J, Rondelli R, Scopinaro M, Staalman C and Plaschkes J: International Society of Paediatric Oncology - SIOPEL 2. Riskadapted treatment for childhood hepatoblastoma. Final report of the second study of the International Society of Paediatric Oncology - SIOPEL2. Eur J Cancer 40: 411-421, 2004.

2. Fuchs J, Rydzynski J, Von Schweinitz D, Bode U, Hecker H, Weinel P, Bürger D, Harms D, Erttmann R, Oldhafer K and Mildenberger H: Study Committee of the Cooperative Pediatric Liver Tumor Study HB94 for the German Society for Pediatric Oncology and Hematology. Cancer 95: 172-182, 2002.

3. Pham TH, Iqbal CW, Grams JM, Zarroug AE, Wall JC, Ishitani MD, Nagorney DM and Moir C: Outcomes of primary liver cancer in children: an appraisal of experience. J Pediatr Surg 42: 834-839, 2007.

4. Czauderna P: Adult type vs. childhood hepatocellular carcinoma - are they the same or different lesions? Biology, natural history, prognosis, and treatment. Med Pediatr Oncol 39: 519-523, 2002.

5. Mikes J, Kleban J, Sacková V, Horváth V, Jamborová E, Vaculová A, Kozubík A, Hofmanová J and Fedorocko P: Necrosis predominated in the cell death of human colon adenocarcinoma HT-29 cells treated under variable conditions of photodynamic therapy with hypericin. Photochem Photobiol Sci 6: 758-766, 2007.

6. Henderson BW, Daroqui C, Tracy E, Vaughan LA, Loewen GM, Cooper MT and Baumann H: Cross-linking of signal transducer and activator of transcription 3- $\alpha$ molecular marker for the photodynamic reaction of cells and tumors. Clin Cancer Res 13: 3156-3163, 2007.

7. Seitz G, Warmann SW, Armeanu S, Heitmann H, Ruck P, Hoffman RM, Fuchs J and Wessels JT: In vitro photodynamic therapy of childhood rhabdomyosarcoma. Int J Oncol 30: 615-620, 2007.

8. Kamuhabwa A, Agostinis P, Ahmed B, Landuyt W, van Cleynenbreugel B, van Poppel $\mathrm{H}$ and de Witte P: Hypericin as a potential phototherapeutic agent in superficial transitional cell carcinoma of the bladder. Photochem Photobiol Sci 3: 772-780, 2004

9. VanderWerf QM, Saxton RE, Chang A, Horton D, Paiva MB, Anderson J, Foote C, Soudant J, Mathey A and Castro DJ: Hypericin: a new laser targeting agent for human cancer cells. Laryngoscope 106: 479-483, 1996.

10. Jichlinski $P$ and Leisinger HJ: Fluorescence cystoscopy in the management of bladder cancer: a help for the urologist! Urol Int 74: 97-101, 2005.

11. Tanaka M, Kawamura K, Fang M, Higashino K, Kishimoto S, Nakabayashi $\mathrm{H}$ and Sato J: Production of fibronection by HUH6 $\mathrm{C} 15$ cell line established from a human hepatoblastoma. Biochem Biophys Res Commun 110: 837-841, 1983.

12. Pietsch T, Fonatsch C, Albrechts S, Maschek H, Wolf HK and Von Schweinitz D: Characterization of the continuous cell line HepT1 derived from a human hepatoblastoma. Lab Invest 74: 809-818, 1996.
13. Morris KM, Aden DP, Knowles BB and Colten HR: Complement biosynthesis by the human hepatoma-derived cell line HepG2. J Clin Invest 70: 906-913, 1982.

14. Hendrickx N, Volanti C, Moens U, Morten Sertenes O, de Witte P, Vandenheede JR, Piette J and Agostinis P: Up-regulation of cyclooxygenase-2 and apoptosis resistance by p38 MAPK in hypericin-mediated photodynamic therapy of human cancer cells. J Biol Chem 278: 52231-52239, 2003.

15. Wada A, Sakaeda T, Takara K, Hirai M, Kimura T, Ohmoto N, Zhou J, Nakamura T, Kobayashi H, Okamura N, Yagami T and Okumura K: Effects of St John's Wort and hypericin on cytotoxicity of anticancer drugs. Drug Metab Pharmacokinet 17: 467-474, 2002.

16. Kamuhabwa AA, Di Mayungu JD, Baert L, D'Hallewin MA, Hoogmartens $\mathbf{J}$ and de Witte PA: Determination of hypericin in human plasma by high-performance liquid chromatography after intravesical administration in patients with transitional cell carcinoma of the bladder. Eur J Pharm Biopharm 59: 469-474, 2005.

17. Tian R, Koyabu N, Morimoto S, Shoyama Y, Ohtani H and Sawada Y: Functional induction and de-induction of Pglycoprotein by St. John's Wort and its ingredients in a human colon cancer adenocarcinoma cell line. Drug Metab Dispos 33: 547-554, 2005.

18. Sarissky M, Lavicka J, Kocanova S, Sulla I, Mirrossay A, Miskovsky P, Gajdos M, Mojzis J and Mirossay L: Diazepam enhances hypericin-induced phototoxicity and apoptosis in human glioblastoma cells. Neoplasma 52: 352-359, 2005.

19. Yee KK, Soo KC and Olivo M: Anti-angiogenic effects of Hypericin-photodynamic therapy in combination with Celebrex ${ }^{\circledR}$ in the treatment of human nasopharyngeal carcinoma. Int J Mol Med 16: 993-1002, 2005.

20. Fu CY, Ng BK, Razul SG, Chin WW, Tan PH, Lau WK and Olivo M: Fluorescence detection of bladder cancer using urine cytology. Int J Oncol 31: 525-530, 2007

21. Siboni G, Weitman H, Freeman D, Mazur Y, Malik Z and Ehrenberg B: The correlation between hydrophilicity of hypericins and helianthrone: internalization mechanisms, subcellular distribution and photodynamic action in colon carcinoma cells. Photochem Photobiol Sci 1: 483-491, 2002.

22. Agostinis P, Vantieghem A, Merlevede W and de Witte PA: Hypericin in cancer treatment: more light on the way. Int $\mathrm{J}$ Biochem Cell Biol 34: 221-241, 2002.

23. Head CS, Luu Q, Sercarz J and Saxton R: Photodynamic therapy and tumor imaging of hypericin-treated sqamous cell carcinoma. World J Surg Oncol 4: 87, 2006.

24. Fuchs J, Rydzynski J, Hecker H, Mildenberger H, Bürger D, Harms D and Von Schweinitz D: German cooperative liver tumour studies HB89 and HB94. Eur J Pediatr Surg 12: 255-261, 2002.

25. Otte JB and de Ville de Goyet J: The contribution of transplantation to the treatment of liver tumors in children. Semin Pediatr Surg 14: 233-238, 2005.

26. Kocanova S, Buytaert E, Matroule JY, Piette J, Golab J, de Witte P and Agostinos P: Induction of heme-oxygenase 1 requires the p38MAPK and PI3K pathways and suppresses apoptotic cell death following hypericin-mediated photodynamic therapy. Apoptosis 12: 731-741, 2007.

27. Pajonk F, Scholber J and Fiebich B: Hypericin - an inhibitor of proteasome function. Cancer Chemother Pharmacol 55: 439-446, 2005.

28. Chen J and Regan RF: Increasing expression of heme oxygenase-1 by proteasome inhibition protects astrocytes from hememediated oxidative injury. Curr Neurovasc Res 2: 189-196, 2005.

29. Czauderna P, Mackinlay G, Perilongo G, Brown J, Shafford E, Aronson D, Pritchard J, Chapchap P, Keeling J, Plaschkes J and Otte JB: Liver Tumors Study Group of the International Society of Pediatric Oncology. J Clin Oncol 20: 2798-2804, 2002.

30. Laakmann G, Jahn G and Schüle C: Hypericum perforatum extract in treatment of mild to moderate depression. Clinical and pharmacological aspects. Nervenarzt 73: 600-612, 2002.

31. Okpanyi SN, Scholl BC and Miltenburger HG: Genotoxizität eines standardisierten Hypericum-Extraktes. Arzneimittelforschung 40: 851-866, 1990 .

32. Traynor NJ, Beattie PE, Ibbotson SH, Moseley H, Ferguson J and Woods JA: Photogenotoxicity of hypericin in HaCaT keratinocytes: implications for St. John's Wort supplements and high dose UVA1-therapy. Toxicol Lett 158: 220-224, 2005. 